\title{
Green Extracellular Synthesis of the Silver Nanoparticles Using Thermophilic Bacillus Sp. AZ1 and its Antimicrobial Activity Against Several Human Pathogenetic Bacteria
}

\author{
Ali Deljou * , Samad Goudarzi \\ Department of Biotechnology, Faculty of Agriculture, Bu-Ali Sina University, Hamedan, Iran \\ ${ }^{*}$ Corresponding author: Ali Deljou, Department of Biotechnology Bu-Ali Sina University, Hameden, Iran. Tel: +98-81398381601, Fax: +98-8134424012, \\ E-mail: agrad@basu.ac.ir
}

Received: September 20, 2015; Revised: December 16, 2015; Accepted: February 15, 2016

\begin{abstract}
Background: Silver nanoparticles (AgNPs) are among the most effective antimicrobial agents that are used in the medicine and pharmaceutics. During the past decades, metal nanoparticles synthesis through application of the biological methods has increasingly been used, as the biologically synthesized particles are mostly non-toxic as well as effective.

Objectives: The main goal for undertaking the present investigation was to evaluate the extracellular synthesis of the AgNPs by a native thermophilic Bacillus Sp. AZ1 that was isolated from a hot spring in Ardebil province. Subsequently the antimicrobial potentials of the nanoparticle was evaluated against several human pathogenic organisms.

Materials and Methods: The biosynthesized AgNPs were confirmed visually by appearance of a dark brown color formation in the mixture as well as silver surface plasmon resonance band by using UV-Visible spectroscopy. The AgNPs were further characterized by SEM, EDX and TEM. The antimicrobial activity of the AgNPs was investigated using Salmonella typhi, Escherichia coli, Staphylococcus epidermis, and Staphylococcus aureus, by applying disk diffusion method.

Results: Identification of the strain AZ1 by the 16S rRNA sequence analysis showed 99\% sequence homology between this strain and B. licheniformis. The obtained UV-Visible spectrum of the aqueous medium containing silver ion, showed a peak at $425 \mathrm{~nm}$ which indicates a correspondence to the plasmon absorbance of the silver nanoparticles. The biosynthesized AgNPs were found to be in the size range of $\sim 7-31 \mathrm{~nm}$ with spherical the shape. Studies regarding the antibacterial effect of the particles showed the highest inhibitory effect against the two strains; E. coli, and S. typhi, respectively. Conclusions: Our study presents a simple green synthesis process for the production of an extracellular nanoparticles which is environmental friendly. Biosynthesis of the AgNPs by a thermophilic bacillus from the hot spring (Qeynarjeh, Ardebil) in Iran with the highest similarity to Bacillus licheniformis is reported for the first time.
\end{abstract}

Keywords: Antimicrobial agents; Biosynthesis; Nanoparticles; 16S rRNA

\section{Background}

Resistance to human pathogens to antibiotics is a major challenge in different areas, such as biomedical and pharmaceutical researches. As examples in this regard, Staphylococcus aureus is resistant to the methicillin, Salmonella typhi to the ciprofloxacin. The problem extends and prevails for other pathogenic bacterial species as well (1-3). The new drug resistant pathogenic bacteria have led to many concerns about ineffectiveness of the antibiotics in addition to the emergence, or reemergence of the multidrug-resistant (MDR) pathogens (4). Several decades ago substances such as silver salts and elemental silver have been used in pri- mary health and curative wound care $(5,6)$, however, with the appearance and development of new antibiotics, the interest to silver as an antimicrobial was drastically reduced $(8,7)$. The AgNPs can be used against a broad range of microbes (9). The AgNPs aims a broad range of targets in the micro-organisms. As well, it was found that, it is unlikely that microbes caould develop resistance against nanosilver as they need to develop a board range of mutations simultaneously to protect themselves (5). The AgNPs can be synthesized using different methods, such as chemical, physical, and biological. Synthesis of nanoparticles by chemical method is simple and economic since it requires short time for syn- 
thesis. Also, synthesis by this method would result in the production of a large amount of the nanoparticles. But nowadays, development of the nature-friendly processes for the nanoparticles synthesis are essential and mainly considered. Thus, developing toxic chemical methods have not gained any point for the synthesis of the nanoparticles. Therefore, biological method of synthesis could be introduced as an alternative method for elimination of such problems (10-12). Until now, the AgNPs were synthesized by bacteria (13), plants (14), fungi (15), Algae (16), and yeasts (17). Inorganic nanoparticles can be generated using micro-organisms through either extracellular or intracellular activities (18). The extracellular biosynthesis of the nanoparticles is economic compared to the intracellular method, because of the simplicity of the production process. The intracellular biosynthesis method requires some additional steps such as application of suitable detergents or ultrasonic treatment for releasing of the synthesized nanoparticles $(19,20)$. In this study, we have used the culture supernatant containing silver nanoparticles of the thermophilic Bacillus sp. AZ1 isolated from hot spring of Qeynarjeh, Ardebil province in Iran. In the present article we report the antimicrobial activity of the AgNPs against a number of human pathogenic bacteria. The nanoparticles were quantified and characterized by UV-Vis spectroscopy, Scanning Electron Microscopy (SEM), Energy Dispersive X-ray Analysis (EDX), and Transmission Electron Microscopy (TEM).

\section{Objectives}

The main goal of this project was to evaluate extracellular synthesis of the AgNPs by a native thermphilic Bacillus Sp. AZ1 which was isolated from a hot spring in Iran and its antimicrobial potentials against several human pathogenic organisms.

\section{Materials and Methods}

\subsection{Isolation and Identification of the Microorganism}

The Bacillus strain used in the present study was isolated from a hot spring in Qeynarjeh, Ardebil provice in the north-west Iran with a water temperature as high as $83^{\circ} \mathrm{C}$. Water samples were collected in a sterile flask and then incubated on nutrient agar plates at $37^{\circ} \mathrm{C}$ for $48 \mathrm{~h}$, subcultures were carried out to obtain single colonies. Identification of micro-organisms was performed according to the current physiological and biochemical assays and amplification of bacterial 16S rRNA genes was performed by applying the universal forward ( $5^{\prime}$-GAG AGT TTG ATC CTG GCT CAG-3') and reverse (5'-CTA CGG CTA CCT TGT TAC GA-3') primers using an Eppendorf thermal cycler. Preparation of the Bacillus gnomic DNA was performed according to Cheng and Ning (2006) with minor modifications to the original protocol (21). The thermal profile was started with initial denaturation at $94^{\circ} \mathrm{C}$ for 4 min followed by 30 cycles of $1 \mathrm{~min}$ at $94^{\circ} \mathrm{C}$ (denaturation), $1 \mathrm{~min}$ at $57^{\circ} \mathrm{C}$ (annealing), $1 \mathrm{~min}$ at $70^{\circ} \mathrm{C}$ (extension), and $7 \mathrm{~min}$ at $70^{\circ} \mathrm{C}$ (Final extension). Dendrogram of the phylogenetic tree was drawn using the Mega-6 software (www.megasoftware.net).

\subsection{Biosynthesis and Characterization of the Silver} Nanoparticles (AgNPs)

To obtain microbial biomass, small amount (oneloop) of the grown colonies were picked up and inoculated into each of Erlenmeyer flasks containing 100 $\mathrm{mL}$ of the liquid LB medium. The Erlenmeyer flasks were incubated in a rotary shaker incubator, with stirring speed of $150 \mathrm{rpm}$ for $24 \mathrm{~h}$ at $40^{\circ} \mathrm{C}$. At the end of each incubation period, the liquid medium was centrifuged at $10,000 \times g$ for $15 \mathrm{~min}$ for removing celldebris. The cell-free supernatant obtained in the previous step was poured into five separate Erlenmeyer flasks equally; four flasks were supplemented with the silver nitrate salt up to $1 \mathrm{mM}$ concentration $(100 \mathrm{~mL}$ final volume). The $5^{\text {th }}$ flask was stored as the negative control for the next step (The cell-free supernatant). One more flask (the $6^{\text {th }}$ flask) was taken as positive control containing $100 \mathrm{~mL}$ of $1 \mathrm{mM}$ of silver nitrate in the distilled water. The Erlenmeyer flasks containing the supernatant mixed with the $1 \mathrm{mM}$ of silver nitrate, were incubated for $24 \mathrm{~h}$ at the same condition that was considered for the microbial biomass growth. To confirm the extracellular formation of the $\mathrm{AgNP}_{\mathrm{s}}$, bioreduction of the silver ions in the medium was monitored using changes in the color from yellow to dark brown. The absorption spectrum of the medium containing reduced silver ions was recorded by a UV-Visible spectrophotometer (Varian Carey 5000) from $300 \mathrm{~nm}$ to $800 \mathrm{~nm}$ at the regular time intervals. The supernatant that was exposed with the $1 \mathrm{mM}$ of silver nitrate, was air dried and the remaining powder was scrapped out for the subsequent characterization of the silver nanoparticles. The morphological characterization and distribution of the nanoparticles was scanned using SEM (FESEM, Model: JSM-6160) and TEM (Philips model CM200) with an accelerating voltages of 20 and $200 \mathrm{KV}$, respectively. Also, the presence of elemental silvers were confirmed by, the air dried pow- 
der was scanned with an EDX that was connected to a SEM (Philips model) instrument.

\subsection{Antibacterial Activity}

The bactericidal capacity of the AgNPs was examined according to the modified Kirby Bauer disk diffusion method (22). The antibacterial assay used against two groups of strains: Staphylococcus aureus, Staphylococcus epidermidis as Gram positive bacteria and Escherichia coli, and Salmonella typhi as Gramnegative bacteria. The suspension cultures of each tested strains were swabbed unevenly onto sterile Mueller-Hinton agar plates by sterile cotton swabs, using a micro pipette, $10 \mathrm{~mm}$ diameter wells were made on agar plate, $100 \mu \mathrm{L}$ of the synthesized AgNP solutions $\left(0.01 \mathrm{mg} \cdot \mathrm{mL}^{-1}\right)$ were poured into each well and incubated at $37^{\circ} \mathrm{C}$. Twenty-four hours after inoculation, the diameter of inhibition zone around each well was recorded.

\section{Results}

\subsection{Identification of Microorganism}

The isolated micro-organism was identified following to the routine biochemical and morphological examinations. Results showed that the isolated strain resembles and relates to the Bacillus species. The isolated strain (AZ1) was a spore-forming, rod-shaped, optionally anaerobic, and Gram-positive bacterium. As well the bacterium was found to be Catalase and Oxidase positive. These tests were conducted according to Bergey's Manual of Systematic Bacteriology (23). PCR amplification showed a length of about $1500 \mathrm{bp}$ of the product (data not shown). Furthermore, sequencing of the PCR amplified 16S rRNA was conducted. The sequence of the $16 \mathrm{~S}$ rRNA gene was aligned against the other recorded sequences in the Gen Bank and it was found $99 \%$ homology to the sequence of the $B$. licheniformis (Figure 1). The phylogenetic tree was drawn by MEGA6 software according to the neighbor-joining method. Finally, the sequence of the isolate was submitted to the NCBI (http://www.ncbi.nlm.nih.gov) and saved under accession number of: KT281606.

\subsection{Biosynthesis of the Silver Nanoparticles $\left(A g N P_{s}\right)$}

The silver nanoparticle synthesis reaction was started when silver nitrate was added to supernatant and incubated at $37^{\circ} \mathrm{C}$. After $6 \mathrm{~h}$ of incubation in the dark room conditions, first change in solution color was

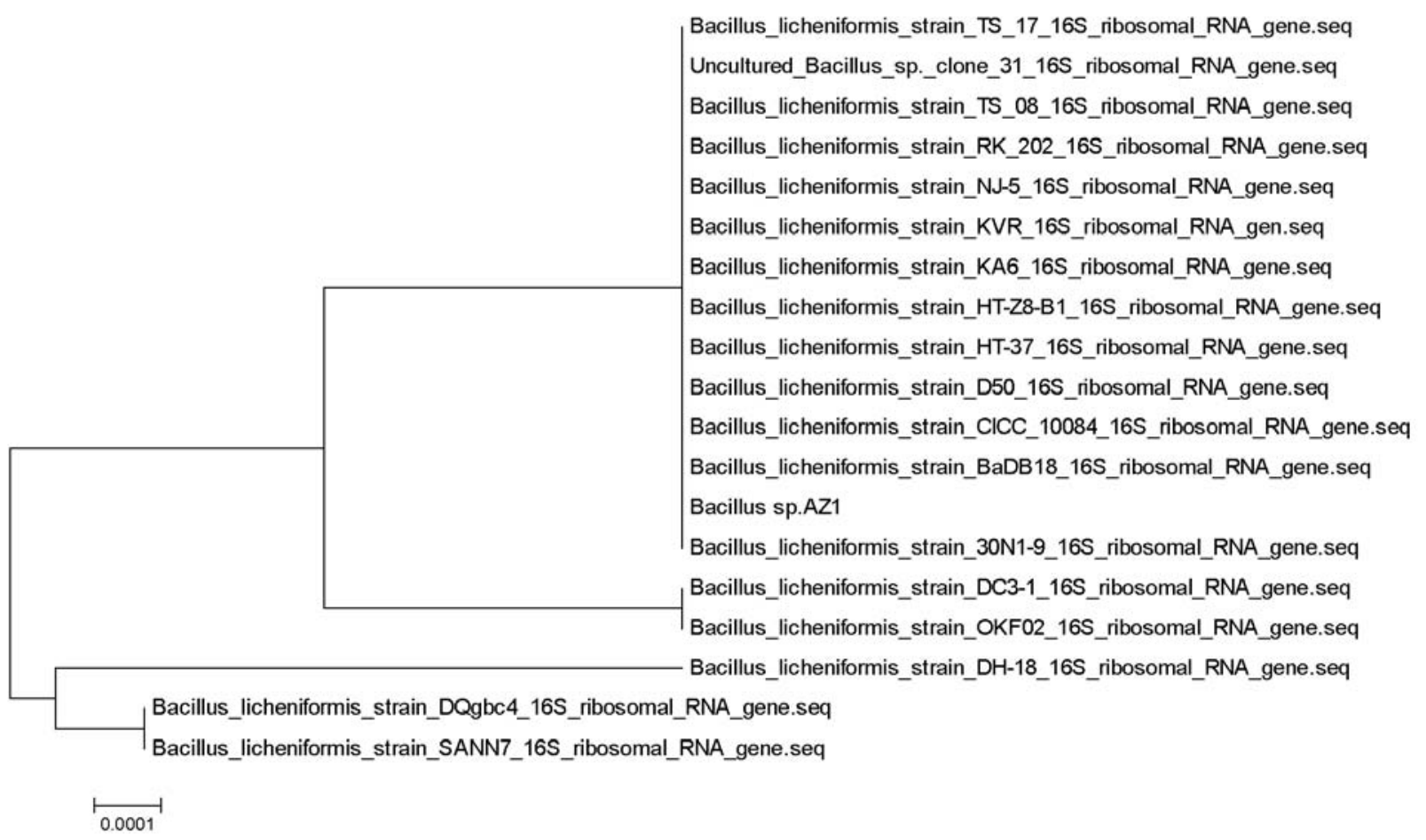

Figure 1. The dendrogram of phylogenetic tree. The dendrogram was drawn according to 16S rRNA genes of the Bacillus sp. AZ1 by Mega 6 software (www.megasoftware.net) 
$\mathbf{A}$

B

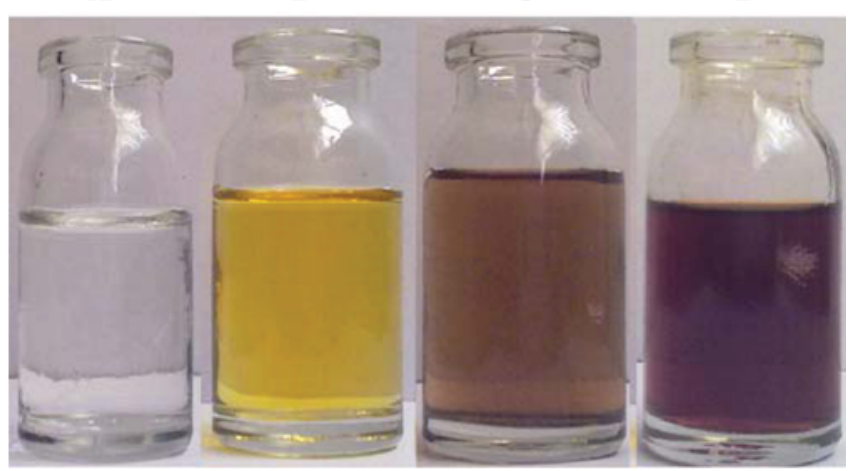

Figure 2. The differential change in the supernatant solution color formation following to the mixing with a solution of $\mathrm{AgNO}_{3}$ $\left(1 \times 10^{-3} \mathrm{M}\right): \mathrm{A}: \mathrm{AgNO}_{3}$ solution $(1 \mathrm{mM})$ only (as positive control), $\mathrm{B}$ : culture supernatant without $\mathrm{AgNO}_{3}$ (as negative control), $\mathrm{C}$ : supernatant mixed with $\mathrm{AgNO}_{3} 1 \mathrm{mM}$ after $6 \mathrm{~h}$, D: supernatant mixed with $\mathrm{AgNO}_{3} 1 \mathrm{mM}$ after $24 \mathrm{~h}$

appeared and continued to develop up to $24 \mathrm{~h}$. The color solutions changed from light yellow to dark brown (Figure 2). The UV-Visible spectrum of the aqueous medium containing silver ion showed a peak at $425 \mathrm{~nm}$ which showed correspondence to the

A
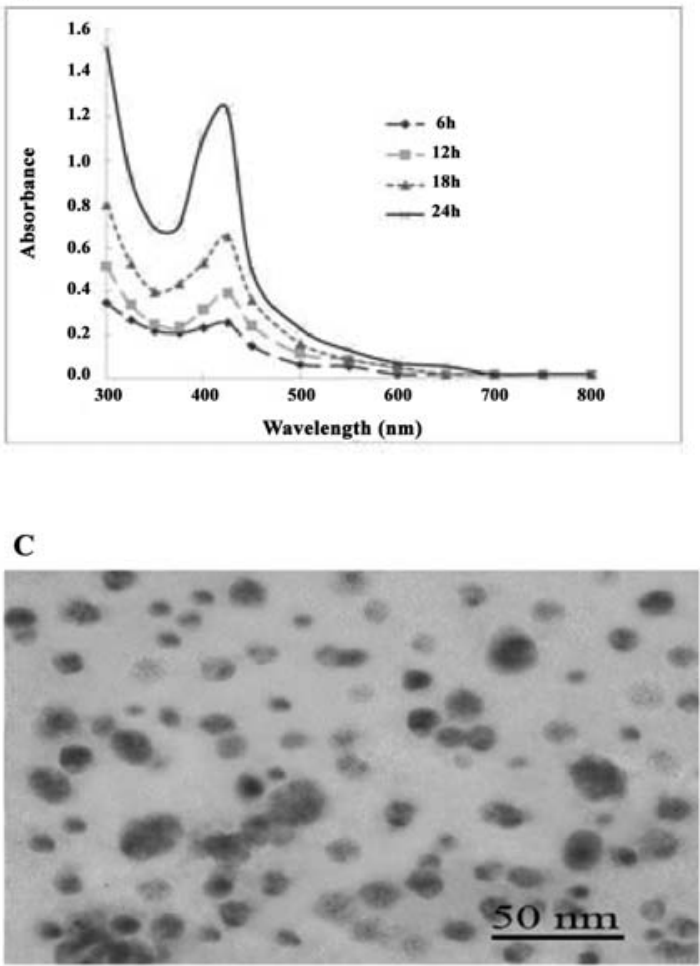

Plasmon absorbance of silver nanoparticles (Figure $3 \mathrm{~A})$. Formation of the silver nanoparticles in range of 7-31 nm was revealed by the SEM (Figure 3B). Much information about distribution and morphological features of AgNPs was obtained by the TEM analysis. TEM micrograph showed AgNPs particles with a wide range of shapes, although a large number of which were spherical in shape. Furthermore, the synthesized silver nanoparticles were found to be either aggregated or as a single granules at certain locations (Figure 3C). Also analysis by TEM has indicated a range of sizes for AgNPs of 9-32 nm, which agrees well with the results obtained by SEM analysis. The presence of AgNPs was further confirmed by EXD analysis following to exposure to the four signals (the elements such as $\mathrm{C}, \mathrm{Ag}, \mathrm{O}$, and $\mathrm{Cl}$ have shown the highest peaks), one of which was in the silver region (Figure 3D). The absorption of the metallic silver nanocrystallites generally shows an absorption peak approximately at $3 \mathrm{KeV}$ (31).

\subsection{Anti Microbial Activity}

Antimicrobial activity of the biosynthesized AgNPs

B

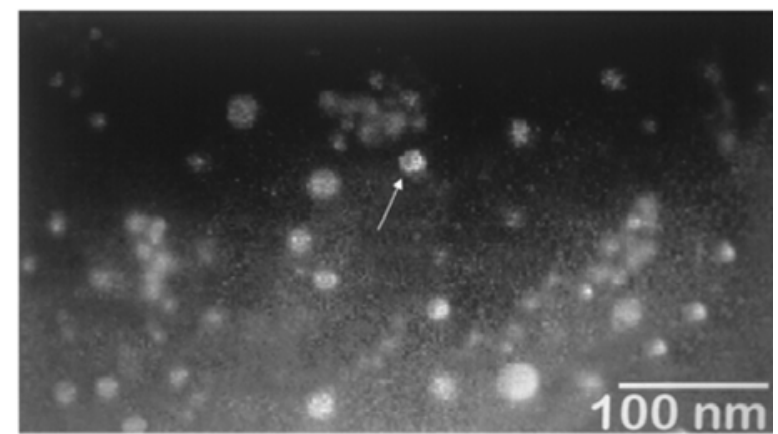

D

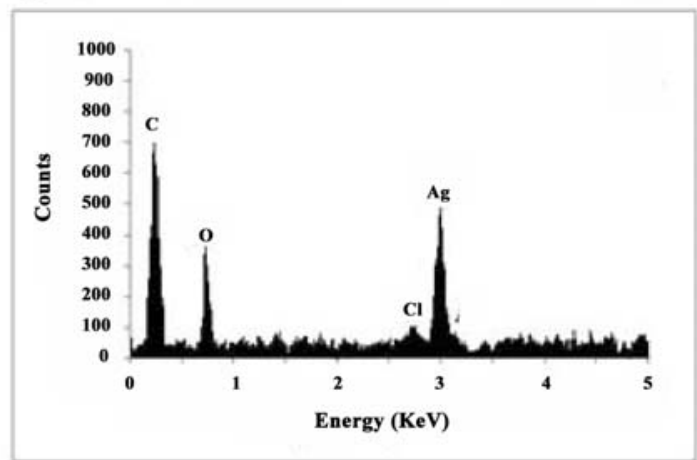

Figure 3. The UV-Visible spectra spectrum of the silver surface Plasmon resonance bands obtained at the different time intervals. B: SEM micrograph shows formation of $\mathrm{AgNPs}$ by culture supernatant mixed with the $\mathrm{AgNO}_{3}\left(1 \times 10^{-3} \mathrm{M}\right)$ after $24 \mathrm{~h}$. C: TEM micrograph obtained for the synthesized AgNPs by the bacterial culture supernatant supplied with the $\mathrm{AgNO}_{3}\left(1 \times 10^{-3} \mathrm{M}\right)$ for a period of $24 \mathrm{~h}$ of the incubation. D: Energy dispersive X-ray spectrum of the AgNPs suspension revealing peaks of the elemental silver 


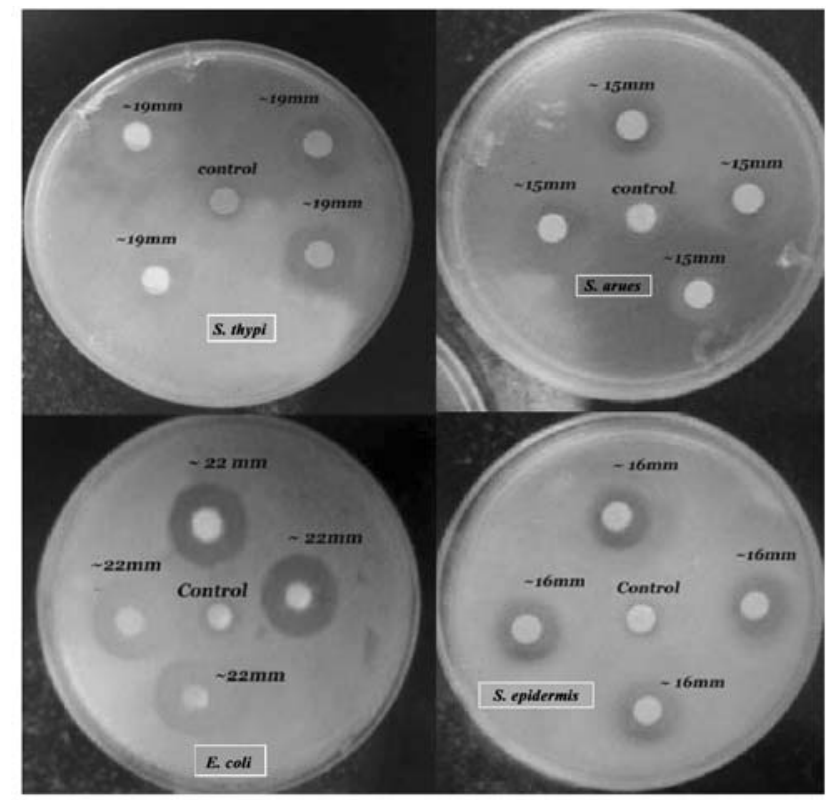

Figure 4. Anitbactiral activity of AgNPs against the four pathogenic bacteria strains by disk diffusion method

was studied against two groups of the Gram-negative (E. coli and S. typhi) and Gram-positive (S. aureus and S. epidemis) bacteria (Figure 4). The silver nanoparticles showed the highest activity against the E. coli with $22 \mathrm{~mm}$ of zone of growth inhibition. Other bacteria tested in this investigation were also affected by AgNPs, however with a lower range of inhibition. For example, the zone of growth inhibition for $S$. typhi was $19 \mathrm{~mm}$, for Staphylococcus epidermidis, and Staphylococcus aurues were 16 and $15 \mathrm{~mm}$, respectively (Figure 5).

\section{Discussion}

In recent years, much attention has been focused on microbes, in order to synthesis nano metal due to the fact that synthesis of the nano particles by microbes is more convenient than other approaches. Also different strains of the bacteria have been subject of studies for the synthesis of the nanparticles such as silver, iron, gold, etc. Moreover, bacteria could easily be genetically manipulated and easy to handle. Among all nanoparticles, the silver ions have always been shown to have an excellent antimicrobial properties. There are numerous reports showing that AgNPs have higher effective antibacterial activity against a number of pathogenic bacteria, fungi, and viruses at a very low concentration, and without any side effects on human body $(4,5,7-9)$. Thus, such a history about capabilities have persuaded us with the idea to use thermophilic

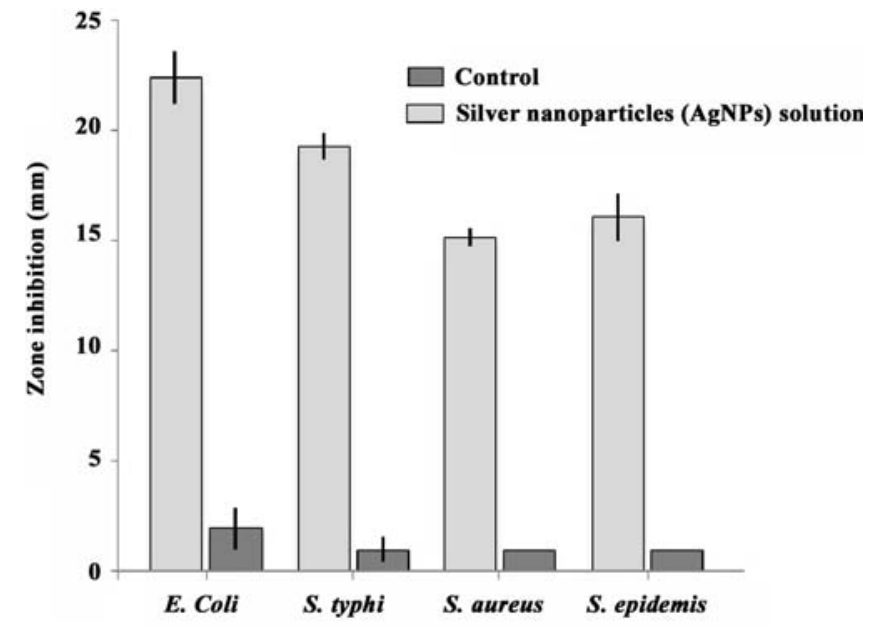

Figure 5. Comparison of the AgNPs growth inhibitory effect on four bacterial strains through measuring the of the zone of growth inhibition against the four pathogenic bacteria strains. Supernatant without $\mathrm{AgNP}_{\mathrm{s}}$ solution was used as the negative control

bacillus for biosynthesis of AgNPs in the present work.

Our study regarding the biosynthesis of silver nanoparticles have proven by ascending changes in the color intensity from yellow to dark brown following a direct correlation with the time of incubation. The change in the color intensity might be due to the excitation of the Surface Plasmon Resonance (SPR) of the silver nanoparticles or reduction of the silver nitrate $(24,25)$. Generally speaking, the AgNPs, due to the presence of the characteristic SPR band at $430 \mathrm{~nm}$ in UV-visible spectroscopy could be measured as an indicator for measurement the amount of AgNPs (26). As it could be seen in the (Figure 2), the appearance of the sharp peaks during color development period (i.e., 6$24 \mathrm{~h}$ ) is due to the surface Plasmon, which is well documented for various metal nanoparticles with the particle sizes ranging from 2 to $100 \mathrm{~nm}$ (27). Furthermore, the optical characteristics, such as peak width and absorption are mainly depend on the other factors including: size, shape, medium, surface charge, the interaction between the particle composition, refractive index of the surrounding medium, particle stability, and surface-adsorbed species (28-30). There are numerous reports regarding extracellular synthesis of the AgNPs by Bacillus species generated with the different sizes $(31,32,36,37)$. Also, in 2008 two studies have been reported on the synthesis of AgNPs using Bacillus licheniformis by Kalishwaralal et al. $(13,19)$. They reported nanoparticles synthesized with an aver- 
age particle size around 40 and $50 \mathrm{~nm}$. The size of the nanoparticles obtained in the present study is much smaller than the nanoparticles synthesized using the same bacterial strain in the other reports. These results show that Bacillus lichniformois AZ1 could be used for the biosynthesis of the smaller AgNPs from silver nitrate. Although the mechanisms that are involved in the generation of the extracellular nanoparticles by microbes are not yet fully understood, but, many researchers believe that microbial synthesis of the metal nanoparticles might be through bioreduction of the metal ions by yet an unknown biochemical reaction. However, it was documented that nitrate reductase could be the main factor for oxidation of the silver ions nanoparticles by the Bacillus licheniformis (19, 20,33). Studies on the antibacterial effects of the AgNPs have been subject of different reports. In this redard the effect of AgNPs on the growth of both Gram positive and Gram negative organisms were investigated. Chudasama et al. (34) and Ramgopal et al. 2011 (35) have reported that $S$. aureus (Gram positive) had a greater antibacterial activity compared to that of $E$. coli (Gram negative). Prakash et al. 2011 (36) have also reported a similar results for antibacterial effects of the AgNPs on Gram negative bacteria (E. coli) and Gram positive (Streptococous pyogene). Whereas, Dipak and Sankar et al. in 2014 (20) and Priyadarshini et al. in 2013 (37) have reported the highest and the lowest zone of inhibition formation against $E$. coli and Staphylococcus respectively. Our studies have shown a higher antibacterial activity against Gram negative organisms which might be due to the thick peptidoglycan layer in the bacterial cell wall, as the peptidoglycan layer of Gram positive bacteria are thicker than that of Gram negative bacteria. The peptidoglycan layers are consisted of linear polysaccharide chains crosslinked with short peptides and leading to the formation of a more rigid structure which provides a strong barrier against the penetration of the AgNPs (38). The detailed mechanism behind the antibacterial activity of AgNPs against other bacteria are not clearly established, but, it seems that the AgNPs penetration and the damage it impose to the bacteria might proceed according to the following steps: In the first step, the nanoparticles break through the permeable outer membrane, and in the second step, the AgNPs enter the internal plasma membrane of the bacteria and inactivate respiratory chain dehydrogenase. The end result of these steps are: leakage of the cell materials (in the first step), inhibition of the respiration and growth of the cell simultaneously, affects on phospholipids, denaturation of proteins and induction of the cell membrane collapse, and finally decomposition and cell death (in the second step according to the above scheme) (39). Various factors may influence the AgNPs toxicity such as: nanoparticle shape and size, surface chemistry, crystallinity, capping agents, as well as other factors such as ionic strength, $\mathrm{pH}$, the presence of ligands, divalent cations, and macro molecules (as environmental factors). For example truncated triangular nanoparticles have stronger antibacterial activity than spherical and rod shaped AgNPs (40). Also, it has been found that there is a direct relationship between a decrease in the size of the nanoparticles and an increased effectiveness of the antibacterial properties. It could be due to the increased number of atoms which are exposed to the surface available for the redox reactions, biochemical, and photo chemical reactions together with the physicochemical interactions of the nanoparticls with bacterial cells (40). Our data show that silver nanoparticls can be produced by the Bacillus licheniformis AZ1 with the size range of 7-31 nm. Thus, the silver nanoparticles presents a simple green synthesis process for production of extracellular nanoparticles which is environmentally acceptable.

\section{Acknowledgements}

Our thanks to the Department of Medical Biotechnology, Hamedan University of Medical Sciences, Iran, as well as Department of Biotechnology, Buali Sina University, Iran for providing us with the required facilities for undertaking this research. Authors also appreciate Ms. Ostad Ahmadi, the Biotechnology laboratory assistant to technician for his kind cooperation with us in doing the present research. The present study was financially supported by a research grant allocated by the Department of Biotechnology, Buali Sina University, Iran.

\section{References}

1. Bruinsma N, Kristinsson KG, Bronzwaer S, Schrijnemakers P, Degener J, Tiemersma E, et al. Trends of penicillin and erythromycin resistance among invasive Streptococcus pneumoniae in Europe. J Antimicrob Chemother. 2004;54(6):10501045. DOI: $10.1093 / \mathrm{jac} / \mathrm{dkh} 458$

2. Voss A, Milatovic D, Wallrauch-Schwarz C, Rosdahl VT, Braveny I. Methicillin-resistant Staphylococcus aureus in Europe. Eur J Clin Microbiol Infect Dis. 1994;13(1):55-50. DOI:10.1007/BF02026127

3. Threlfall EJ. Antimicrobial drug resistance in Salmonella: problems and perspectives in food-and water-borne infections. FEMS Microbiol Rev. 2002;26(2):148-141. DOI: 10.1111/j.1574-6976. 
2002.tb00606.x

4. Tenover FC. Mechanisms of antimicrobial resistance in bacteria. Am J Med. 2006;119(6):10-3. DOI:10.1016/j.amjmed.2006.03. 03.011

5. Sukdeb P, Kyung TY, Myong SJ. Does the antibacterial activity of silver nanoparticles depend on the shape of the nanoparticle? A study of the gram-negative bacterium E. coli. Appl Environ Microbiol. 2007;73(6):1720-1712. DOI: 10.1128/ AEM.02218-06

6. Chudasama B, Vala A K, Andhariya N, Mehta RV, Upadhyay R V. Highly bacterial resistant silver nanoparticles: synthesis and antibacterial activities. J Nanopart Res. 2010;12(5):16851677. DOI: $10.1007 /$ s11051-009-9845-1

7. Chen X, Schluesener H J. Schluesener. Nanosilver: a nanoproduct in medical application. Toxicol Lett. 2008;176(1):12-1. DOI: 10.1016/j.toxlet.2007.10.004

8. Rai M K , et al. Silver nanoparticles: the powerful nanoweapon against multidrug-resistant bacteria. $J$ Appl Microbiol. 2012;112(5):852-841. DOI: 10.1111/j.1365-2672.2012.05253.x

9. Kim JS, Kuk E, Yu KN, Kim JH, Park SJ, Lee HJ, et al. Antimicrobial effects of silver nanoparticles. Nanomedicine: NBM. 2007;3(1):101-95. DOI: 10.1016/j.nano.2006.12.001

10. Prabhu S, Eldho K. Silver nanoparticles: mechanism of antimicrobial action, synthesis, medical Poulose applications, and toxicity effects. Int Nano Lett. 2012;2(1):10-1. DOI: 10.1186/2228-5326-2-32

11. Singhal G, Bhavesh R, Kasariya K, Sharma AR, Singh RP. Biosynthesis of silver nanoparticles using Ocimum sanctum (Tulsi) leaf extract and screening its antimicrobial activity. $J$ Nanopart Res. 2011;13(7):2988-2981. DOI: 10.1007/s11051010-0193-y

12. Iravani Korbekandi H, Mirmohammadi SV, Zolfaghari SB. Synthesis of silver nanoparticles: chemical, physical and biological methods. Res Pharm Sci. 2014;9(6):406-385.

13. Kalishwaralal K, Deepak V, Ramkumarpandian S, Nellaiah H, Sangiliyandi G. Extracellular biosynthesis of silver nanoparticles by the culture supernatant of Bacillus licheniformis. Mater Lett. 2008;62(29):4413-4411. DOI: 10.1016/j.matlet. 2008.06.051

14. Vilchis-Nestor AR, Sánchez-Mendieta V, Camacho-López MA, Gómez-Espinosa RM, Camacho-López MA, Arenas-Alatorre J A. Solventless synthesis and optical properties of $\mathrm{Au}$ and $\mathrm{Ag}$ nanoparticles using Camellia sinensis extract. Mater Lett. 2008;62(17):3105-3103. DOI: 10.1016/j.matlet.2008.01.138

15. Gholami Shabani M, Akbarzadeh A, Norouzian D, Amini A, Gholami-Shabani Z, ImaniA, Chiani M, Riazi Gh, ShamsGhahfarokhi M, Razzaghi M. Antimicrobial Activity and Physical Characterization of Silver Nanoparticles Green Synthesized using Nitrate Reductase from Fusarium oxysporum. Appl Biochem Biotechnol. 2014;172(8):4098-4084. DOI: $10.1007 / \mathrm{s} 12010-014-0809-2$

16. Govindaraju K, Basha SK, Kumar VG, Singaravelu G. Silver, gold and bimetallic nanoparticles production using single-cell protein (Spirulina platensis) Geitler. Mater Sci. 2008;43(15):5122-5115. DOI: 10.1007/s10853-008-2745-4

17. Kowshik M, Ashtaputre S, Kharrazi S, Vogel W, Urban J, Kulkarni SK, Paknikar KM. Extracellular synthesis of silver nanoparticles by a silver-tolerant yeast strain MKY3.
Nanotechnology 2002;14(1):95-86. DOI: 10.1088/09574484/ $14 / 1 / 321$

18. Samadi N, Golkaran D, Eslamifar A, Jamalifar, H, Fazeli MR, Mohseni FA. Intra/extracellular Biosynthesis of Silver Nanoparticles by an Autochthonous Strain of Proteus mirabilis Isolated from Photographic Waste. J Biomed Nanotechnol. 2009;5(3):253-247. DOI: 10.1166/jbn.2009.1029

19. Kalishwaralal K, Ramkumarpandian BR, Venkataraman D, Bilal M, Gurunathan S. Biosynthesis of silver nanocrystals by Bacillus licheniformis. Colloids Surf B. 2008;65(1):153-150. DOI:10.1016/j.colsurfb.2008.02.018

20. Diapak P, Sanker NS. Extracellular Synthesis of Silver Nanoparticles Using Pseudomonas aeruginosa KUPSB12 and Its Antibacterial Activity. Jordan $J$ Biol Sci. 2014;7(4):250-245. DOI: 10.12816/0008246

21. Cheng HR, Ning J. Extremely rapid extraction of DNA from bacteria and yeasts. Biotechnol Lett. 2006:28(1):59-55. DOI: 10.1007/s10529-005-4688-z

22. Bauer AW, Kirby WM, Sherris JC, Turck M, Antibiotic susceptibility testing by a standardized single disk method. Am J Clin Pathol. 1966;45(1):496-493.

23. Boone DR, Castenholz RW, Brenner DJ, Leadbetter JR, Whitma WB, Noel R, et al. Bergey's Manual ${ }^{\circledR}$ of Systematic Bacteriology. Springer Science \& Business Media. 2005; p. 58-62.

24. Mulvaney P. Surface plasmon spectroscopy of nanosized metal particles. Langmuir 1996;12(3):800-788. DOI: 10.1021/ la9502711

25. Gopinath V, MubarakAli D, Priyadarshini S, Priyadharsshini NM, Thajuddin N, Velusamy P. Biosynthesis of silver nanoparticles from Tribulus terrestris and its antimicrobial activity: a novel biological approach. Colloids Surf B. 2012;96(1):74-69. DOI: 10.1016/j.colsurfb.2012.03.023

26. Naik RR, Stringer SJ, Agarwal G, Jones SE, Stone MO. Biomimetic synthesis and patterning of silver nanoparticles. Nat Mater. 2002;1(3):169-172. DOI: 10.1038/nmat758

27. Henglein A. Physicochemical properties of small metal particles in solution: microelectrode reactions, chemisorption, composite metal particles, and the atom-to-metal transition. J Phys Chem. 1993;97(21):5471-5457. DOI: $10.1021 / \mathrm{j}$ $100123 \mathrm{a} 004$

28. Keibig U, Vollmer M. Theoretical Considerations. In Optical properties of metal clusters. Springer Berlin Heidelberg. 1995; p. 13-201. DOI: 10.1007/978-3-662-09109-8-2

29. Underwood S, Mulvaney P. Effect of the solution refractive index on the color of gold colloids. Langmuir 1994;10(10):3430-3427. DOI: 10.1021/la00022a011

30. Nair B, Pradeep T. Coalescence of nanoclusters and formation of submicron crystallites assisted by Lactobacillus strains. Cryst Growth Des. 2002;2(4):298-293. DOI: 10.1021/ cg0255164

31. Sunkar S, Nachiyar CV. Biogenesis of antibacterial silver nanoparticles using the endophytic bacterium Bacillus cereus isolated from Garcinia xanthochymus. Asian Pac J Trop Biomed. 2012;2(12):959-953. DOI: 10.1016/S2221-1691 (13)60006-4

32. Saravanan M, Anil KV, Sisir KB. Rapid biosynthesis of silver nanoparticles from Bacillus megaterium (NCIM 2326) and 
their antibacterial activity on multi drug resistant clinical pathogens. Colloids Surf B. 2011;88(1):331-332. DOI: 10.1016/j.colsurfb.2011.07.009

33. Durán N, Marcato PD, Durán M, Yadav A, Gade A, Rai M. Mechanistic aspects in the biogenic synthesis of extracellular metal nanoparticles by peptides, bacteria, fungi, and plants. Appl Microbiol Biotechnol. 2011;90(5):1624-1609. DOI: 10.1007/s00253-011-3249-8

34. Chudasama, Bhupendra, Vala AK, Andhariya N, Mehta RV, Upadhyay RV. Highly bacterial resistant silver nanoparticles: synthesis and antibacterial activities. J Nanopart Res. 2010;12(5): 1685-1677. DOI: 10.1007/s11051-009-9845-1

35. Ramgopal M, Saisushma CH, Abobaker M. Alhasin. A facile green synthesis of silver nanoparticles using soap nuts. Res J Microbiol. 2011;6(5):438-432. DOI: 10.3923/jm.2011.332.438

36. Prakash A, Sharma S, Ahmad N, Ghosh A, Sinha P. Synthesis of AgNps By Bacillus cereus bacteria and their antimicrobial potential. J Biomater Nanobiotechnol. 2011;2(2):162-156.
DOI: $10.4336 /$ jbnb.2022.22020

37. Priyadarshini S, Gopinath V, Priyadharsshini NM, MubarakAli D, Velusamy P. Synthesis of anisotropic silver nanoparticles using novel strain, Bacillus flexus and its biomedical application. Colloids Surf B. 2013;102(1):237-232. DOI: 10.1016/j.colsurfb. 2012.08.018

38. Mahendra R, Yadav A, Aniket Gade. Silver nanoparticles as a new generation of antimicrobials. Biotechnol Adv. 2009;27(1):83-76. DOI: 10.1016/j.biotechadv.2008.09.002

39. Li WR, Xie XB, Shi QS, Zeng HY, You-Sheng OY, Chen YB. Antibacterial activity and mechanism of silver nanoparticles on $E$. coli. Appl Microbiol Biotechnol. 2010;85(4):1122-1115. DOI: 10.1007/s00253-009-2159-5

40. Marambio J, Hoek MVC, Hoek MVE. A review of the antibacterial effects of silver nanomaterials and potential implications for human health and the environment. $J$ Nanopart Res. 2010;12(5):1551-1531. DOI: 10.1007/s11051-010-9900-y 